\title{
Franklin Valley defended
}

SIR - On 29 September (p.354), Nature published a letter by S.J. Paterson, chief geologist of the Tasmanian Hydro-Electric Commission (HEC) which reveals a lack of understanding of archaeological evidence and interpretation, which issued a threat to the funds available for archaeologists and which questioned the objectivity of archaeologists opposed to the Franklin dam, among whom I was mentioned by name.

I first published an evaluation of Tasmanian prehistory in 1961, and wrote in defence of the Franklin region in 1981 when I learned of its Ice Age habitation sites and noted the meagre and dismissive six sentences on prehistory in the HEC 1979 Draft Environmental Report.

Dr Paterson deplores that the Australian Association of Consulting Archaeologists advised its members to refuse to undertake salvage archaeology, thereby depriving HEC of assistance. He omits that this advice was given as recently as February. From the first archaeological discoveries early in 1981, HEC had two years in which to employ archaeologists.

Dr Paterson also neglected to explain that this advice, in a letter from the association's president to Premier Gray, was given after the then Federal Minister for Home Affairs and Environment had offered massive support for salvage archaeology but on lines that violated both archaeological ethics and the ICOMOS international charter on the protection of monuments and sites, of which Australia is a signatory. The letter also stated succinctly the reasons that led me to oppose dam construction - HEC's inadequate assessment of the environmental impact, its failure to reconsider the dam project even after the recognition of the archaeological importance of the site and its decision to push ahead with roads and construction camps regardless of possible archaeological damage.

The purpose of the frantic field survey conducted while the High Court case was being prepared was not simply archaeological, and does not justify the destruction of one area by the discovery of another. Dr Paterson quotes an impressive number of caves discovered, but experience at Franklin, where only two major archaeological sites and several minor ones were located in some 100 caves and shelters, suggests that other valleys are likely to contain relatively few major archaeological places. Ironically, if the funds spent on this helicopter-assisted but archaeologically leaderless survey had been spent during previous years, the entire region could have been evaluated.

It is to be hoped that assessment will now be carried out, once HEC observes Tasmanian law and provides full details of all discoveries to the Tasmanian Parks and Wildlife Service. Even if these valleys do contain numerous sites, however, this will merely emphasize the region's truly unique quality. Such a complex of caves preserving Ice Age evidence is unsurpassed anywhere. Dr Paterson claims to refute my assertion that the Franklin caves may compare in importance with those in southwest France, but he evidently believes that these latter caves are significant only because of their painted walls. However, deep archaeological deposits in the Dordogne have been reexcavated for over a century and provided the classic type sites for most Upper Palaeolithic cultures. They have been the yardstick by which cultural origins have been judged. The remarkable fact is that Tasmanian evidence challenges this Europocentric version of prehistory. Tasmania should provide evidence for the reconstruction of technological, economic and social life during those same millennia when modern people colonized the globe.

In human terms, these remote places possess remarkable qualities. When people first reached the Franklin Valley, the world was in the grip of its last deep freeze. Those hardy pioneers in this then-open country were the most southerly colonists on the Earth's surface. The limestone and dampness have combined to preserve evidence in these caves in a remarkable manner. Less than a cubic metre of deposit in Kutikina cave produced more stone artefacts and animal bones than the total of finds in all other excavated Tasmanian Ice Age sites, including Cave Bay cave and two in the Florentine Valley.

These sites are also unique in their context. Here are entire river systems occupied in the Ice Age and the sites left intact since then. What was the form of the original colonization? Were all caves occupied simultaneously, or seasonally for specialized functions? Were some sites living places and others spiritual abodes? Dr Paterson considers such caves "merely record occupation by hunting parties" but this undervalues the insight they may give into early society.

The international reality is that southwest Tasmania fully satisfies the criteria for World Heritage listing. Together with two other Australian World Heritage designations, the Kakadu and Willandra regions, there is an opportunity for studying in the Southern Hemisphere complementary examples of adaptation to monsoonal tropics, semi-arid interior and cool temperate forest habitats.

The challenge facing Tasmania is to stop ignoring its past and to develop land management policies that encourage respect for environmental and cultural values.

\section{Department of Prehistory,} Australian National University, Canberra, ACT 2600, Australia

\section{India's science base}

SIR - In his letter on "Indian expatriates" (Nature 3 November, p.10), Dr Malviya makes generalizations ("scientists in India are not terribly science-minded") which imply that his opinions are widely shared. Any scientist, Indian or otherwise, with such attitudes must face the hostility of the Indian scientific community. It is well known that more than half of the Indian expatriates stay on abroad not because they are "terribly science-minded" (mediocre Indian scientists have been employed and offered tenure abroad) but because of the money and the "good life" - which is perfectly understandable.

Indians who oppose the return of their colleagues are not afraid they will have to re-evaluate their scientific reserch. They may merely be protesting at the deal handed out to them. They have chosen to stay and conduct research, and their efforts should not go unrecognized. If the Indian Government is prepared to invest money, why does it not do so to improve existing facilities and working conditions rather than to build a "technology city"? Why should the attractive incentive be offered only to the expatriate?

Those Indian scientists who have chosen to stay in India even when they have had opportunities to work abroad deserve appreciation for trying to carry on research with the meagre funds that trickle into science in India. Are they to blame?

I also disagree with Dr Malviya's rather pompous declaration that their research is of little importance internationally. A recent survey in Current Contents (26, 33; 15 August 1983) shows that India is the most cited of Third World countries and it ranks eighth in the world for the number of articles contributed by its researchers in the international journals sampled. Many Indian scientists try to carry out research in applied fields, for which there is more money available and which has more applications in a developing country like India than does basic research. In addition, Indian scientists make many contributions to journals of theoretical physics and biology.

Dr Malviya's letter seems to me to be little more than the self-justification of a mildly guilt-ridden person. Being an Indian scientist abroad hardly gives one the authority to air views on one's Indian counterparts who have chosen to stay and work against overwhelming odds. It is considerably easier to comment on the need for a technology city in India if one is on the obviously greener side of the fence. The decision to create a technology city may not be the best, but certainly not for the reasons put forward by Dr Malviya.

AMEeta KeLEKAR

St Louis University, School of Medicine, St Louis, Missouri 63103, USA 